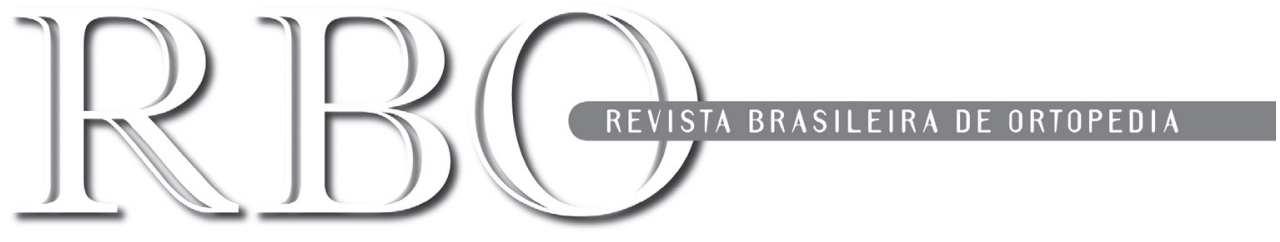

\title{
Editorial
}

\section{Nível de Evidência}

A editoração científica no Brasil tem evoluído muito e, a cada momento, novos critérios são considerados. Essa busca da melhora da qualidade editorial tem a ver com a Capes que, para pontuar a produção científica, exigiu níveis cada vez mais altos de qualidade das revistas. Atualmente, esses critérios estão sendo discutidos na AMB, que está se reunindo e estudando com os editores de todas as revistas científicas do Brasil as exigências da Capes. Embora haja exageros por parte da Capes, no nosso ponto de vista, houve um estímulo à melhora da qualidade das revistas brasileiras.

Um critério de qualidade muito utilizado nas revistas científicas modernas é o nível de evidência. As revistas de padrão internacional utilizam cinco níveis de evidência. O menor nível de evidência dos trabalhos científicos é o relato de casos e o maior é a metanálise ou trabalhos com randomização e seguimento perfeitos. Há uma tendência a considerar que esses níveis podem ser utilizados para classificar os trabalhos científicos em melhores ou piores. Acreditamos que esses parâmetros são mais uma ferramenta para a análise crítica dos trabalhos, sem representar um critério de qualidade.

Para podermos compreender essa forma de qualificação de trabalhos, vamos simular a utilização dos níveis de evidência para um projeto de viagem. Imaginemos que estamos com um período de férias disponível e gostaríamos de fazer uma viagem por um determinado tempo e que vamos pesquisar qual seria o melhor destino utilizando como método de seleção os níveis de evidência.

A opinião de um amigo sobre um novo destino turístico, diferente dos diversos lugares comuns, seria, na nossa comparação com a análise de um trabalho científico, o relato de caso ou a descrição de uma nova técnica, que é o pior dos níveis de evidência.

O relato de várias pessoas sobre um mesmo destino com um percentual de opiniões positivas e outro de negativas seria comparável ao nosso relato de uma série de casos que, pelo fato de não ter um critério comparativo, tem um valor um pouco maior que o relato de caso, mas ainda desprezível na análise de um trabalho científico ou, no nosso exemplo, de um destino de viagem.

Para atingirmos um nível de aceitação razoável teríamos que considerar um grupo de pessoas que foram a dois destinos diferentes em épocas próximas e que relatassem de forma comparativa vários aspectos, como custo, restaurantes, passeios, etc. Um dos destinos a ser considerado na comparação deveria ser um local de turismo tradicional. Na nossa comparação, esses seriam os trabalhos comparativos de qualidade média, pois os de alta qualidade exigiriam que as pessoas viajassem no mesmo período, para os dois lugares, o que é impossível. Esse mesmo critério de qualificação é exigido nos trabalhos comparativos, pois precisamos operar os pacientes com duas técnicas diferentes na mesma época, embora consideremos que a técnica proposta é superior quando comparada com a outra que obviamente foi feita no passado. É interessante que uma das técnicas seja um padrão-ouro no tratamento da patologia estudada. Não podemos comparar dados obtidos no passado com os atuais, nesse tipo de nível de evidência. 
O ideal seria que os nossos informantes viajassem depois de formularmos a pergunta, pois a opinião seria prospectiva e não retrospectiva, fato que desqualifica um pouco o nível de evidência da informação.

Finalmente, para fazermos uma viagem considerada ideal, teríamos duas opções:

- a primeira seria utilizar um número grande de publicações (o maior possível) feitas com os critérios estabelecidos e comuns a todas as viagens, que seria uma revisão sistemática ou uma metanálise do tema;

- a segunda seria organizar um grupo de viajantes que iriam a dois destinos desconhecidos, selecionados por sorteio, e que ao final da viagem expressassem suas opiniões sobre os mesmos itens.

Esse seria o nível mais alto de evidência para a nossa opção de viagem.

Acredito que, com as limitações que essa comparação tem, fica fácil de entender que não há, segundo esses critérios, viagens/trabalhos científicos melhores ou piores. O que há, na verdade, é um tipo de viagem/trabalho científico escolhido com um grau de confiabilidade maior. 0 grau de confiabilidade é um dos critérios de qualidade.

O relato de caso/descrição de técnica deve ser considerado útil para situações novas e inusitadas. É inegável que essas situações ocorrem e devem ser divulgadas.

A série de casos traz a experiência que, se considerada segundo critérios aceitos de resultados, tem muito valor. A identificação dos autores e da origem do trabalho confere confiabilidade ao trabalho. Foi assim que a maioria dos tratamentos que utilizamos foi introduzida na nossa prática.

O critério comparativo, sem dúvida nenhuma, é muito importante, nem sempre é possível e ético, mas quando é, traz confiabilidade maior ao trabalho científico.

A metanálise é um retrato da situação de maior consenso no momento, feito de forma técnica, sem nenhum envolvimento do autor/autores com a técnica avaliada. 0 trabalho duplo-cego randomizado com seguimento maior que $80 \%$ dos indivíduos avaliados é o estudo que mais profundamente analisa uma pesquisa.

Gostaríamos de introduzir, inicialmente por informação espontânea dos autores, o nível de evidência do trabalho enviado para publicação na RBO.

Ao final do texto propomos um critério de nível de evidência para trabalhos que estudam resultados terapêuticos. Esses critérios não serão utilizados para qualificar trabalhos, serão apenas uma informação a mais para o leitor.

Para que haja a evolução, a contestação e a busca de novos rumos, temos que utilizar todos os tipos de evidência, segundo o projeto que pretendemos realizar, sem considerar que um é melhor ou pior que o outro. Se isso não for assim, nunca ninguém irá a Petra e Miami não suportará o afluxo turístico.

A seguir, temos os níveis de evidência que consideraremos para trabalhos que estudam resultados terapêuticos.

\section{NÍVEIS DE EVIDÊNCIA PARA PUBLICAÇÃO NA RBO}

Nível I - Trabalho randomizado com técnica adequada, com seguimento de pelo menos $80 \%$ dos casos e estudo estatístico compatível; ou metanálise com técnica adequada e resultados consistentes de trabalhos nível I.

Nível II - Trabalho randomizado com randomização parcial ou feita com técnica imperfeita ou com seguimento de menos de $80 \%$ dos casos ou estudo estatístico imperfeito. Estudo prospectivo comparativo. Metanálise de trabalhos nível II ou metanálise de trabalhos nível I com resultados inconsistentes.

Nível III - Estudo de casos retrospectivo comparativo ou metanálise de trabalhos nível III.

Nível IV - Descrição de série de casos, com análise de resultados, sem estudo comparativo.

Nível V - Descrição de casos, descrição de técnica cirúrgica ou opinião de especialista. 